\title{
AN ASSESSMENT OF ERGONOMIC WORKSTATIONS AND PAIN AMONG COMPUTER USERS IN A NIGERIAN UNIVERSITY COMMUNITY
}

\author{
Journal website at; \\ http://mrtbjournal.org/index.php/njmr/issue/current/showToc \\ ${ }^{+}$OE Johnson, ${ }^{+}$AT Onigbinde, ${ }^{\text {SA }}$ Onasanya , ${ }^{+}$AAI Emechete, *TO Gbela \\ Medical Rehabilitation Department, College of Health Sciences, Obafemi Awolowo University, \\ Ile Ife, Osun State, Nigeria." \\ Science Education Department, Faculty of Education, University Of Ilorin \\ Correspondence to: \\ O.E. Johnson \\ Email:obnik2001@yahoo.com
}

\begin{abstract}
SUMMARY
Background \& Objective: Computer usage is a trend in technology advancement that is common with virtually all jobs and it predisposes all users to avoidable musculoskeletal injuries. This study aimed at determining Computer Workstation (CW) ergonomics among computer users in Obafemi Awolowo University Ile-Ife, Nigeria. Also the distributions of musculoskeletal pain experienced by computers users were determined.
\end{abstract}

Methods: One hundred and fifty (150) participants were recruited using cluster sampling technique. Participants must have been users for 6 months, working 15 hours per week. The participant's bio-data were recorded and CW were identified and measured for footrest, casters, keyboard height, seat height, monitor height, seat back angle and arm angle. They were asked if they were experiencing pain, its location and cause. Data were analysed using descriptive statistics.

Results: Results obtained showed that 23 (15.3\%) of the $\mathrm{CW}$ had 5 casters, and just $3(2 \%)$ had footrests while there were, $130(86.7 \%)$ and $104(69.3 \%)$ with ideal chair and keyboard heights respectively. Also, there were 130 $(86.7 \%)$ and $136(90 \%)$ with ideal monitor height and seat back angle respectively. Results showed that $105(70 \%)$ of the participants experienced pain and mostly $(52.4 \%$ of the $70 \%$ ) in the back with mean pain intensity 7 on a 10 point pain scale. Participants; (38) $25.3 \%$, believed that CW arrangement was the cause of the pain.

Conclusion: This study concluded that majority of the CW did not meet the standard description of CW and majority of the computer had pain in the low back as at the time of study.
Keywords: Ergonomic workstation, Computer users, Musculoskeletal Pain, Nigerian University

\section{INTRODUCTION}

Computer, a hallmark of technology advancement has ushered in a new genre of occupational health problems via improper ergonomic arrangement (Suparna, et al, 2005). The computer has been identified as a device that has a unique potential to improve the quality of health (Idowu et al, 2003). A good work ergonomic arrangement will allow any computer user to work in natural, ideal typing posture that will minimize the risk of developing any injury (Hedge, 2007). Positioning or using a computer improperly can lead to various injuries from short term discomfort or headache to potentially debilitating conditions like carpal tunnel syndrome. The posture assumed while working in an office can put a strain on the body but there are things that can be done to be more comfortable and to help prevent injuries i.e. workstation ergonomics. Literatures have shown that ideal seat height is between $38 \mathrm{~cm}-53 \mathrm{~cm}$ while keyboard height is between $65 \mathrm{~cm}-81 \mathrm{~cm}$ (Jackson, 1999). Also, monitor height, seat back and arm angles are observed to be normal when they are $90 \mathrm{~cm}-115 \mathrm{~cm}, 90$ degrees and 90 degrees respectively, (Jackson, 1999). Studies showed that levels of ergonomic knowledge and the priority given to ergonomic computer use were low irrespective of location (Sawyer, 2004)

According to Rudakwetch et al, (2001), ergonomic intervention reduces the prevalence of musculoskeletal symptoms by an average of $40 \%$. Interventions aimed at reducing musculoskeletal disorders due to computer workstation should be directed at either physical or ergonomic factors. Good posture is the basis of good workstation ergonomic and the evaluations of postures 
and postural re-education as formed part of physiotherapy education and practice since its earliest days (Jones and Bakers, 1996). The postures a man adopts should involve little expenditure of energy, minimal stress and strain which should be conducive for maximum efficiency of the body (Jones and Bakers, 1996).

There is an upsurge in computer usage of recent with a consequent increase prevalence of musculoskeletal disorders in the neck, upper extremities and low back (Kryger et al, 2003; Adedoyin et al, 2004). Back pain and other musculoskeletal pain have been observed to be common among computer users (Adedoyin et al, 2004). The increase prevalence has been link to factors like poor workstation design, duration of daily keyboard and mouse usage, assumed posture during computer work, (Palmer et al, 2001; Kryger et al, 2003; Sillanpaa et al, 2003). There has been an extensive study of these disorders in the developed nations of the world but they are appeared to be few available studies in this environment. Similarly, there is scarcity of studies that evaluated computer workstation among computer users. This study was therefore aimed at determining computer workstation among computer users in Obafemi Awolowo University, Ile Ife, Nigeria. Musculoskeletal pain intensity, distribution and cause, and was also determined

\section{METHODOI,OGY}

\section{Materials}

Subjects: The study involved 150 male and female participants. They were computer users who had used a computer for a minimum of 6 months and constituently working for 3 hours per day or 5 hours per week as described by (Supama et al, 2005). They were recruited from 6 faculties in Obafemi Awolowo University (OAU), Ile Ife, and Osun State, Nigeria.

\section{Instruments:}

Bathroom weighing scale, height meter, to measure heights and weights respectively and visual analogue scale to rate pain, tape measure to measure lengths and goniometer to quantify angles.

\section{Research Design \& Sampling Technique:}

The research design for this study was the cross sectional survey design. The cluster sampling technique was used to randomly select the faculties that were used.

\section{Procedure}

An ethical clearance for the research was sought and obtained from the research committee of the Obafemi Awolowo University Teaching Hospital Complex. The computer workstation was assessed for ergonomics safety measures available and these included foot rest, casters, and elbow rest. Participants' physical characteristics (body weights, and heights) and the pain intensities were measured.
Computer Workstation: These following variables were measured

* Seat height: This was measured as distance from the floor to the top seat surface using the tape measure. Ideal seat height is between $38 \mathrm{~cm}-53 \mathrm{~cm}$. (Jackson, 1999).

* Keyboard height: This was measured as distance from the floor to the keyboard tray using the tape measure. Ideal keyboard height is between $65 \mathrm{~cm}-$ $81 \mathrm{~cm}$ (Jackson, 1999).

* Monitor height: This was measured as distance from the floor to the edge of the monitor using the tape measure. Ideal monitor height is between $90 \mathrm{~cm}$ $115 \mathrm{~cm}$ (Jackson, 1999).

* Seat back angle: This was measured as the angle between the horizontal and vertical bars of the chair using the goniometer. Ideal seat back angle is 90 degrees (Jackson, 1999).

* Arm angle: This was measured as the angle of the elbow joint while working on the computer using the goniometer. Ideal arm angle is 90 degrees. (Jackson, 1999).

Computer work station chairs were also assessed for five casters and foot rest (Jackson, 1999). Participants were assessed on; pain severity and location(s) during the use of computer, and the cause(s) of pain.

\section{Data Analysis}

Data were analyzed using descriptive statistics of mean, standard deviation, frequencies and percentages.

\section{RESULTS}

\section{Physical characteristics of the participants}

One hundred and fifty male and female computer users recruited from six randomly selected faculties of the Obafemi Awolowo University Ile Ife participated in the study. The physical parameters of the participants are presented in Table 1 . The mean, age weight, and height were $42.2 \pm 7.7,68.8 \pm 9.8$ and $1.60 \pm 0.1$ respectively.

Table 1: Physical Characteristics of the Participants

\begin{tabular}{llll}
\hline & Range & Mean & \pm SD \\
\hline Age $(\mathrm{n}=150)$ & $28-59$ & 42.4 & \pm 7.7 \\
Height $(\mathrm{N}=150)$ & $1.50-1.86$ & 1.4 & \pm 0.1 \\
weight $(\mathrm{N}=150)$ & $25-101$ & 68.8 & \pm 9.8 \\
\hline
\end{tabular}

Key- $\mathrm{N}=$ Number of subjects, $\mathrm{SD}=$ Standard Deviation the visual analogue pain rating scale of 10 (Table 5).

The period of computer usage in years among the computer users were arranged in the range of 1-5yrs, 6-10yrs, 11$15 y$ rs and $16-20 y r s$. Seventy five $(50 \%), 68(45.3 \%), 6(4.0 \%)$, and $1(0.1 \%)$ fell within the grouped years respectively. Also, the length of computer usage in hours were arranged into the range of 1-5yrs and 6-10yrs with the frequency 
and percentage of $120(80 \%), 30(20 \%)$ respectively (Table 2). Also, the results showed that 105 participants representing $70 \%$ of the whole group experienced pain at work while using the computer but only $45(30 \%)$ were without pain.

The locations of pain among 105 computer users who claimed to have pain are presented in Table 3 . The locations were; the eyes, neck, back, back and neck and wrist. Results showed that $55(52.4 \%)$ complained of pain mostly in the back. Twenty seven (25.7\%) subjects could not explain the source of the pain, while the same number claimed that the computer workstation arrangement must have been responsible for the pain. Also, 24(22.9\%) participants opined that having musculoskeletal pain was due to the long length hours of work. The results also showed that $30(28.6 \%)$ rated their pain as $3,37(35.2 \%)$ as $4,25(24.8 \%)$ as 5 and only $1(1 \%)$ of the participants experienced pain level of 7 on the visual analogue pain rating scale of 10 (Table 3 ).

Table 2: Physical Characteristics of the Subject

\begin{tabular}{llll}
\hline $\mathbf{N}=150$ & Range & $\mathbf{F}$ & $\%$ \\
\hline $\begin{array}{l}\text { Length of } \\
\text { computer use } \\
\text { in years }\end{array}$ & $1-5$ & 75 & 50 \\
& $6-10$ & 68 & 45.3 \\
& $11-15$ & 6 & 4 \\
$\begin{array}{l}\text { Length of } \\
\text { computer use in }\end{array}$ & & & \\
Hours per day & $16-20$ & 1 & 0.7 \\
& $1-5$ & 105 & 70 \\
& $6-10$ & 45 & 30 \\
\hline
\end{tabular}

KEY- N $=$ Number of subjects, $\mathrm{SD}=$ Standard Deviation

Table 3:Frequency showing the Location of Pain, Cause of Pain and the rating of Pain usuing VAS

\begin{tabular}{llll}
\hline N=150 & Range & F & \% \\
\hline Location of Pain & Eyes & 4 & 3.8 \\
& Neck & 15 & 14.3 \\
& Back & 55 & 52.4 \\
& Back and Eyes & 8 & 7.6 \\
& Back and Neck & 15 & 14.3 \\
& Wrist and Back & 8 & 7.6 \\
Pain rating using & & & \\
VAS & 2 & 3 & 2.9 \\
& 3 & 30 & 28.6 \\
& 4 & 37 & 35.2 \\
& 5 & 26 & 24.8 \\
& 6 & 8 & 7.6 \\
Causes of Pain & Don't Know & 1 & 1 \\
& Furniture & 27 & 25.7 \\
& Body Weight & 27 & 25.7 \\
& Sitting Posture & 4 & 7.6 \\
& Sitting for Long & 13 & 3.8 \\
& Long Length of & & 12.4 \\
& Hours at work & 24 & 2.9 \\
& Monitor & 2 & 1.9 \\
\hline
\end{tabular}

Key $: N=$ Number of subjects

$\mathrm{F}=$ Frequency

$\%=$ Percentage
The period of computer usage in years among the computer users were arranged in the range of 1-5yrs, 610yrs, $11-15 y$ rs and 16-20yrs. Seventy five (50\%), $68(45.3 \%), 6(4.0 \%)$, and $1(0.1 \%)$ fell within the grouped years respectively. Also, the length of computer usage in hours were arranged into the range of $1-5 \mathrm{yrs}$ and $6-10 \mathrm{yrs}$ with the frequency and percentage of $120(80 \%), 30(20 \%)$ respectively (Table 3 ). Also, the results showed that 105 participants representing $70 \%$ of the whole group experienced pain at work while using the computer but only $45(30 \%)$ were without pain.

The locations of pain among 105 computer users who claimed to have pain are presented in Table 4 . The locations were; the eyes, neck, back, back and neck and wrist. Results showed that $55(52.4 \%)$ complained of pain mostly in the back. Twenty seven (25.7\%) subjects could not explain the source of the pain, while the same number claimed that the computer workstation arrangement must have been responsible for the pain. Also, 24(22.9\%) participants opined that having musculoskeletal pain was due to the long length hours of work (Table 5). The results also showed that $30(28.6 \%)$ rated their pain as $3,37(35.2 \%)$ as $4,25(24.8 \%)$ as 5 and only $1(1 \%)$ of the participants experienced pain level of 7 on the visual analogue pain rating scale of 10 (Table 5).

One hundred and twenty one $(80.7 \%)$ participants were aware of the need for a proper table and chair for the computer workstation while $29(19.3 \%)$ were not. Six $(50.7 \%)$ departments involved in the study were not aware of the proper table and chair for computer workstation while $74(49.3 \%)$ were aware. Twenty three (15.3\%) out of the 150 computer chairs have five casters the ideal for a proper ergonomic workstation (Jackson, 1999). One hundred and twenty seven ( $84.7 \%$ ) computer workstations did not have 5 casters, while 147 (98\%) did not have foot rests (Table $4)$.

The ideal measurement of computer furniture was compared with the computer furniture measurement at the different workstation involved in the study. One hundred and thirty $(86.7 \%)$ had the ideal seat height while $20(13.3 \%)$ did not. One hundred and four $(69.3 \%)$ had the ideal keyboard height while $20(13.3 \%)$ had the ideal monitor height/ $136(90 \%)$ had seat back angle, while $15(10 \%)$ did not. $114(76 \%)$ had ideal arm angles while $36(24.5 \%)$ did not.

Table 4: Frequency and Percentage Table of Five Casters and Foot Rest

\begin{tabular}{llll}
\hline $\mathbf{N = 1 5 0}$ & Range & F & $\mathbf{\%}$ \\
\hline Five Casters & Yes & 23 & 15.3 \\
& No & 127 & 84.7 \\
Foot Rest & Yes & 3 & 2 \\
No & 147 & 98 & \\
\hline
\end{tabular}

KEY- N= Number of subjects, $F=$ Frequency, $\%=$ percentage 


\section{DISCUSSION}

Result obtained sliowed that (105) $70 \%$ of the subjects involved in the study had pain while using the computer. This might be because a lot of them probably assumed bad postures when working on the computer as evidenced by the poor common computer working environment observed in this study. Even though most of the computer workstations observed in this study had chairs and tables with proper heights and angles, they were still not up to standard in literature because most of the stations had less than five casters and no footrest, which are basic part of proper computer chairs and tables. Sawyer (2004) opined that levels of ergonomic knowledge and the priority given to ergonomic computer use were low irrespective of location. Good posture according to Hedge (1993) is one, which most naturally suits the body, and it is the basis of good workstation ergonomics and the best way to avoid a computer-related injury. . Thirty eight $(25.3 \%)$ out of the participants who claimed to have pain believed their furniture arrangement was the cause of the pain. Only few chairs had 5 casters, the standard for a proper ergonomic workstation and very few of the whole 150 computer workstation had a foot rest. According to Caple (2007), a foot rest is useful to address lower back fatigue when sitting for long periods. Pushing the feet into the footrest helps to push the back into the angled backrest of the chair. Idowu et al, (2005) also opined that a computer chair should have a 5-leg base (casters) for stability

This study found that computer users in the University experienced pain in the eyes, neck, wrist but majority experienced pain in the back. The mean pain intensity observed in this study on a 10 point pain scale was 7 . This value appears to be high, suggesting that pain experienced by computer users in this study was high. Adedoyin et al (2004) found out that the most common complaints by computer users were low-back pain (78\%), finger pain (69\%) and neck pain (67\%). All these were identified with poor ergonomic inappropriate furniture as the cause of pain among the participants studied. Kryger et al (2003) similarly observed that there is an upsurge in computer usage with a consequent increase prevalence of musculoskeletal disorders in the neck, upper extremities and low back.

\section{CONCLUSION}

It was concluded that only few of the computers had standard 5 casters and foot rests. The computer stations however met expected standard for seat and keyboard heights, monitor and seat back angles. Computer users experienced pain mostly in the back, ard mostly between 3 and 5 on a ten point scale.

\section{REFERENCES}

- Adedoyin R.A, Idowu B.O, Adagunodo R.E and Idowu P.A (2004): Musculoskeletal pain associated with the use of Computer system in Nigeria. International Journal of Pain, Symptoms control and Palliative Care, ISSN 1528-8277.

- Caple D. (2007): Computer User Guide. Occupational Health, Safety and Environment, MONASH University.

- Hadge A. (2007): Ergonomic Guidelines for Arranging a Computer Workstation 10steps for users. Inttp:// ergo.human.comell.edu/ergoguide.html.

- Hedge A. (1993): Arranging your Workstation Ergonomically http://www.smednet.com/

- Idowu B.O, Adedoyin R.A, Adagunodo R.E, (2005): Computer Related Repetitive Strain Injuries. Journal of the Nigerian Society of Plysiotlerapy. 15(1).

- Idowu B, Ogunbodede E. (2003): Information and Communication Technology in Nigeria: The Health Sector Experience, Journal of Information Technology Impact 3(2) $69-76$.

- Jackson D. (1999): CUASA Ergonomics booklets, make your work area work for you. www.caut.ca/causa/ ergonomics

- Jones K and Barker K (1996): Human Movement Explained. First Edition London, Butteworth, Heinemain LTD, 275 289.

- Kryger A.L., Anderson J.H., Lassen C.F., Brandth L.P.A, Vilstrup 1, Overaard E., Thomson J.F, nad Mikkelsen S (2003): Does Computer use pose an Occupational Hazard for Forearn; arm the NUDATA study Occupational and Environmental Medicine 60.

* Palmer K., Cooper C., Walker-Bone K., Syddall H., Coggon D. (2001): Use of Keyboards and symptoms in the neck and arm: Evidence from a national survey. Occupational Medicine 51 (6): 392 -395.

- Price, D.D.; McGrath R, Raffi A and Buckingham Buckinghan B (1983): The Validation of Visual Analogue Scales as ratio Scales Measures for Chronic and Expcrimental Pain 17, 45-56

2 Rudakewyah M.L. and Valent-weitz (2001): Effects of an Ergononic Intervention on Musculoskeletal Discomfort among Office Workers. Proceedings of the Human Factors and Ergonomics Society 4th Annual Meeting. San Diego.

- Sawyer J.K (2004): Application of Ergonomic Principles to the Use of Desktop Keyborad Operated Computcr Technology within Organization; A Doctoral Thesis of Public Health. University of Adelaide. www.thesis. library.adelaide.edu.au.

- Sillanpaa J., Huikko S., Nyberg M., kivi P, Uitti J. (2003): Effect of Work with Visual Display Units on Musculoskeletal Disorders in the office environment. Occupational Medicine 53(7): 443-451.

- Suparma K, Sharma AK, Khandekar J,(2005): Occupational Health Problems and Role of Ergonomics in Information Technology. Professionals in National Capital Region, 9(3), $111-114$.

- World Health Organization Journal (2007): Sedentary Lifestyle: a Global Public Health Problem.

- William H. Kincaid, P.E. (2007): Ergononics and Overweight Employees. http://www.occupationalhazards.com. 